\title{
Drugs for improving esophageal mucosa defense: where are we now and where are we going?
}

\author{
Edoardo Savarino ${ }^{a}$, Patrizia Zentilin' ${ }^{\text {, Elisa Marabotto }}$, Gaia Pellegattab, Claudia Coppo ${ }^{\text {, }}$ \\ Matteo Brunacci ${ }^{b}$, Pietro Dulbecco ${ }^{b}$, Vincenzo Savarino ${ }^{b}$
}

University of Padua; University of Genoa, Italy

\section{Abstract}

\begin{abstract}
In the past, the attention of physiologists and doctors has been mainly focused on the key role of acid in the pathogenesis of gastroesophageal reflux disease (GERD), but increasing evidence that $20-40 \%$ of reflux patients respond not at all or only partially to proton pump inhibitors (PPIs) has underlined the concept that factors other than acid are implicated in its development and the elicitation of symptoms. Among these, impaired mucosal integrity, particularly in most patients with non-erosive reflux disease, has recently been reincluded and the reinforcement of defensive mechanisms and/or its protection has been reappointed as a renewed therapeutic target for the management of GERD patients. In this review we will summarize the existing knowledge of the old and novel compounds able to produce this therapeutic effect, including sucralfate, alginate-based drugs, and a new medical device consisting of hyaluronic acid and chondroitin sulfate dispersed in a bioadhesive carrier, together with the potential indications for their use. It is to be stressed, however, that, although these compounds may represent a real alternative to PPI therapy in GERD, the combination of mucosal protection with acid suppression may help manage many cases with a partial or unsatisfactory response to PPIs alone.
\end{abstract}

Keywords Gastroesophageal reflux disease, histology, non-erosive reflux disease, impedance-pH monitoring, mucosal integrity

Ann Gastroenterol 2017; 30 (5): 1-7

\section{Introduction}

Gastroesophageal reflux disease (GERD) is a pathological condition highly prevalent in western countries [1-4]. Several recent epidemiological studies have reported a prevalence as high as $15-30 \%$, depending on the population studied (European/US or Asiatic) [1-4]. It has long been considered as a disease related to the presence of an increased reflux of gastric acid into the esophagus; accordingly, therapy was focused mainly on the use of antisecretory drugs [5].

${ }^{\mathrm{a} G a s t r o i n t e s t i n a l ~ U n i t, ~ D e p a r t m e n t ~ o f ~ S u r g e r y, ~ O n c o l o g y ~ a n d ~}$ Gastroenterology, University of Padua, Padua (Edoardo Savarino); ${ }^{\mathrm{b}}$ Gastrointestinal Unit, Department of Internal Medicine and Medical Specialties, University of Genoa, Genoa (Patrizia Zentillin, Elisa Marabotto, Gaia Pellegatta, Claudia Coppo, Matteo Brunacci, Pietro Dulbecco, Vincenzo Savarino), Italy

Conflict of Interest: None

Correspondence to: Vincenzo Savarino, Division of Gastroenterology, Department of Internal Medicine, University of Genoa, Viale Benedetto XV, 6, 16100 Genova, Italy, e-mail: vsavarin@unige.it

Received 19 May 2017; accepted 24 July 2017; published online 17 August 2017

DOI: https://doi.org/10.20524/aog.2017.0187
Proton pump inhibitors (PPIs), the most powerful compounds for the suppression of gastric acid secretion, have replaced $\mathrm{H}_{2}$ antagonists ( $\mathrm{H}_{2} \mathrm{RAs}$ ) in the treatment of GERD, and nowadays are considered the first-choice therapy for both the acute and the chronic management of the various forms of GERD [6]. However, it has been shown that the interplay of multiple pathophysiological factors, mainly represented by altered motor functions, results in an excess of acid in the wrong place, namely in the esophagus (Fig. 1), which is not familiar with acid and pepsin contact [7]. Accordingly, most clinical trials in the past that aimed to assess the efficacy of PPIs were carried out in patients with esophageal mucosal erosions (ERD) and the main therapeutic endpoint was the ability to heal them in the shortest time possible [8]. Other investigations have assessed the success of PPIs in keeping the esophageal mucosa healed in the long term [9], as erosions tend to relapse early after the withdrawal of acute treatment.

However, in the past decade it has been realized that ERD represents a minority of patients with GERD $(<30 \%)$, whereas the majority of them are included in the non-erosive reflux disease (NERD) phenotype, characterized by typical reflux symptoms, mainly heartburn, without any esophageal mucosal lesion visible on upper endoscopy [10]. This latter group of patients respond to PPIs less than the former with 
ERD [11]; this rather surprising result arises from the fact that the NERD population is extremely heterogeneous from a pathophysiological point of view [12].

The subdivision into several subgroups with various functional patterns has been made possible by the application in clinical practice of the modern technique of impedance- $\mathrm{pH}$ monitoring [13], which has rapidly become the most useful technique for investigating gastroesophageal reflux [14]. For the first time, it helped us not only detect liquid and gaseous

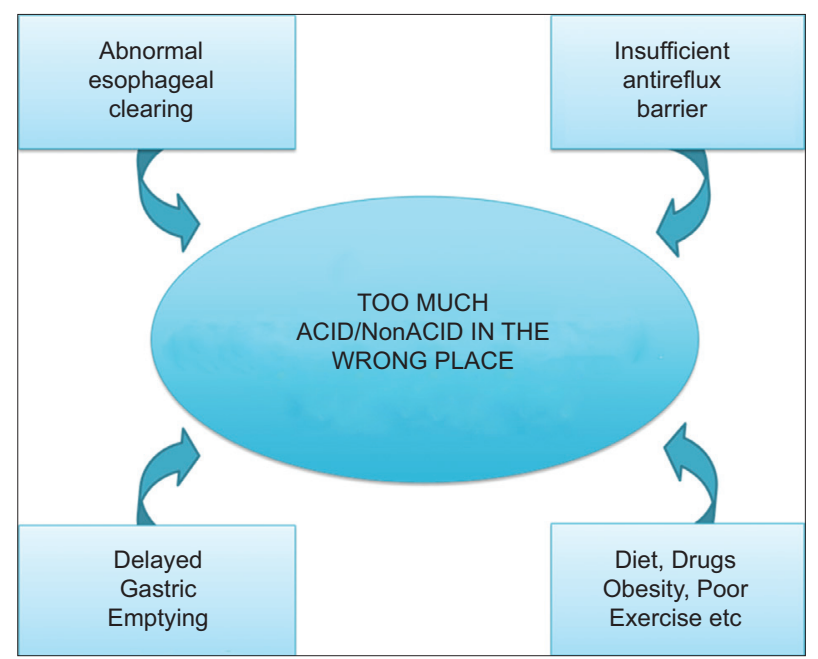

Figure 1 Main pathogenetic factors implicated in gastroesophageal reflux disease refluxes, but also distinguish acid, weakly acidic and weakly alkaline reflux events in the esophagus [15]. Nowadays, we are able to measure precisely both the global quantity of acid and nonacid reflux and the correlation between symptoms and the various chemical types of reflux [16], thus greatly improving the diagnostic yield of the method [17].

Today, NERD can be subdivided into three well-defined conditions (Fig. 2) on the basis of their esophageal acid exposure and positive or negative symptom association analysis [18]: a) patients with true NERD, who present an excess of acid in the esophagus (approx. 40\%); b) patients with reflux hypersensitivity (RH), who have normal acid but a positive correlation between symptoms and acid or weakly acidic reflux (approx. 20-30\%) or both; and c) patients with functional heartburn (FH), who have normal acid, no symptom-reflux correlation and so far, given the lack of evidence of reflux underlying their symptoms, do not pertain to the realm of GERD (approx. 30\%). More recently, the last iteration of the Rome criteria for functional esophageal disorders (Rome IV) proposed that RH patients should also be considered as having functional disease, rather than GERD; however, some concerns remain about this novel classification, since the data in support of it are poor [19].

Nevertheless, in keeping with the classification based on endoscopy + impedance-pH, it is not surprising that $20-40 \%$ of patients with typical symptoms of GERD respond not at all or only partially to PPI therapy, thus emphasizing the fact that factors other than acid are responsible for the generation of their symptoms [20]. For instance, in patients with NERD and RH, one of the most important mechanisms involved in symptom

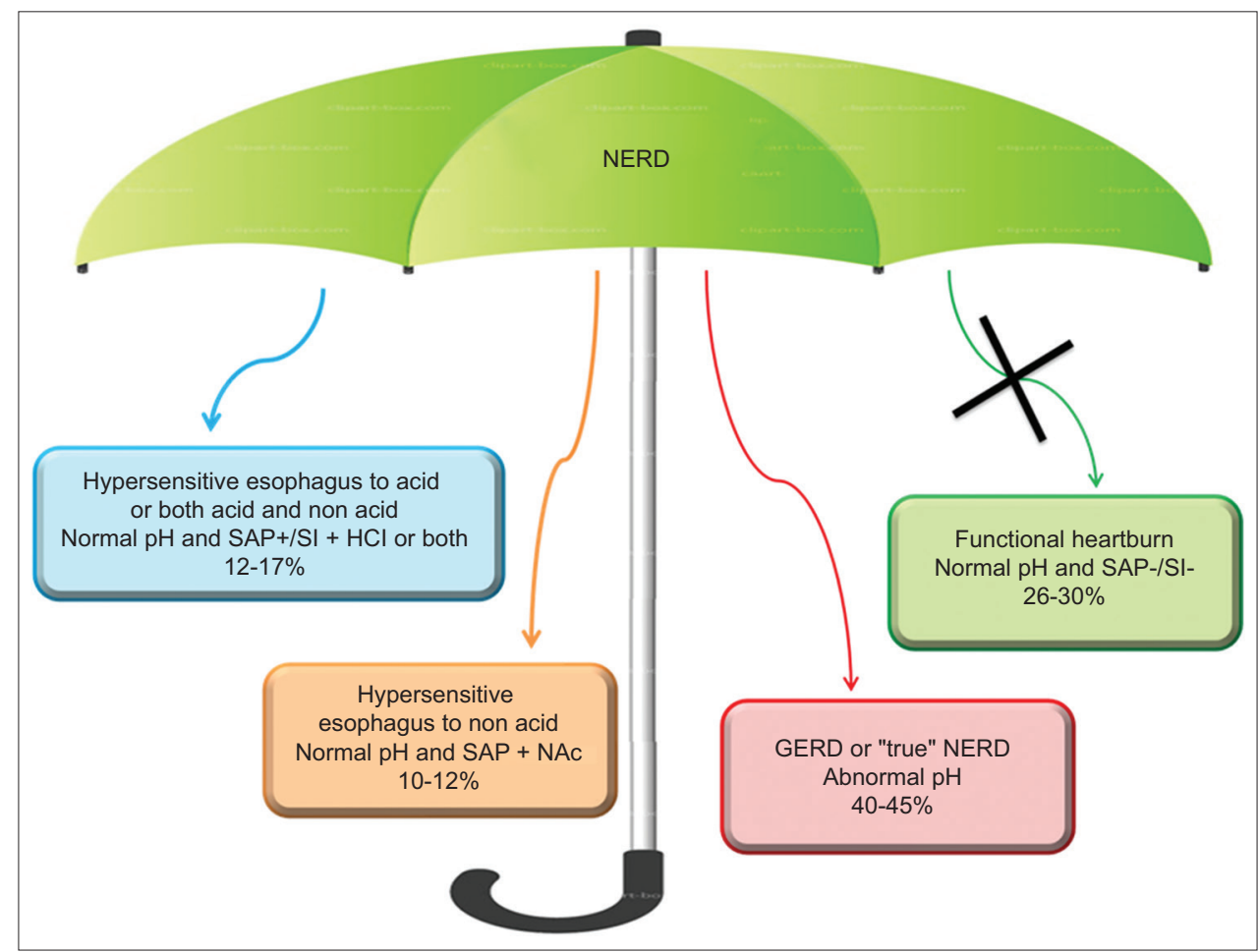

Figure 2 Pathophysiological heterogeneity of non-erosive reflux disease (NERD) by means of 24-h impedance-pH monitoring: the NERD umbrella concept 
generation has been shown to be the presence of microscopic esophagitis (i.e. histological abnormalities) [21]; therefore, the detection of dilated intercellular spaces (DIS) has been strongly suggested as a histological marker of reflux disease [22]. In fact, many studies using electron microscopy have shown that the presence of DIS is a common finding in patients with NERD $[23,24]$, but this histological alteration can also be detected by means of light microscopy [25], which has the advantage of analyzing and scoring all the histopathological abnormalities characterizing microscopic esophagitis [26]. Indeed, we found in a recent study [27] that microscopic esophagitis, including DIS, is considerably less represented in controls (15\%) and in patients with FH (13\%) than in patients with RH (65\%) and in those with increased esophageal acid exposure (77\%), thus highlighting the potential role of this analysis in supporting the diagnosis of GERD or FH (Fig. 3) [28].

The above histological damage is relevant for inducing symptom development, because it permits acid and other substances to reach and activate esophageal chemosensitive receptors [29]. In particular, DIS can be caused by many components of refluxate, including not only acid, but also weakly acidic refluxes [30], which explains why different chemical types of reflux are able to produce the same typical symptoms, such as heartburn, regurgitation and acid taste [31]. This alteration can be partially resolved by medical anti-reflux therapy [32] with consequent improvement of symptoms, thus suggesting that it might be a potential target for both medical and surgical therapies in patients with GERD [33].

\section{Protection of esophageal mucosal integrity}

In patients with PPI-refractory symptoms, the development and adoption of drugs able to act on different pathophysiological mechanisms other than acid have been advocated in recent years.
In particular, great attention has been paid recently to the use of pharmacological or physical agents aimed at potentiating the defensive properties of esophageal mucosa, a therapeutic target so far overlooked [34]. The integrity of esophageal mucosa depends on a subtle balance between aggressive (acid, pepsin, biliary and pancreatic secretions) and defensive (saliva contents, secretions of mucus and bicarbonates, and good mucosal permeability) factors. Moreover, the resistance of esophageal mucosa is due to multiple factors, which are grouped into three categories: 1) preepithelial (salivary secretion, secretion of muco-bicarbonates); 2) epithelial (stratified cells of squamous epithelium that reduce the retro-diffusion of hydrogen ions and favor their neutralization); and 3) post-epithelial (mainly the mucosal blood supply supporting the mechanisms of cellular repair).

There are many studies showing that the defensive properties of the esophagus are impaired in most patients with GERD, particularly in those with NERD, who do not bear macroscopic mucosal lesions [35]. Indeed, the presence of DIS, which correlates strongly with transepithelial electrical resistance and reduced basal impedance (BI) levels detected in distal esophagus, is common in patients with NERD with or without abnormal esophageal acid exposure (i.e. true NERD and RH) and reflects the impairment of their mucosal barrier [36]. In particular, BI levels have been proposed as a marker of mucosal integrity, since they can be easily calculated using impedance- $\mathrm{pH}$ tracings, high resolution impedance manometry or a new endoscopic device [37-39]. Low BI levels are observed in cases of impaired esophageal mucosal resistance (erosive esophagitis, Barrett's esophagus, eosinophilic esophagitis) and patients with NERD also present lower BI values than healthy subjects and those with FH $[40,41]$. Some authors have proposed a simplified method for measuring BI [42], called mean nocturnal BI (MNBI), which consists of measuring $\mathrm{BI}$ at 3 or $5 \mathrm{~cm}$ above the lower esophageal sphincter during overnight rest by calculating the mean BI during three 10-min time periods around 1, 2, and 3 a.m., when

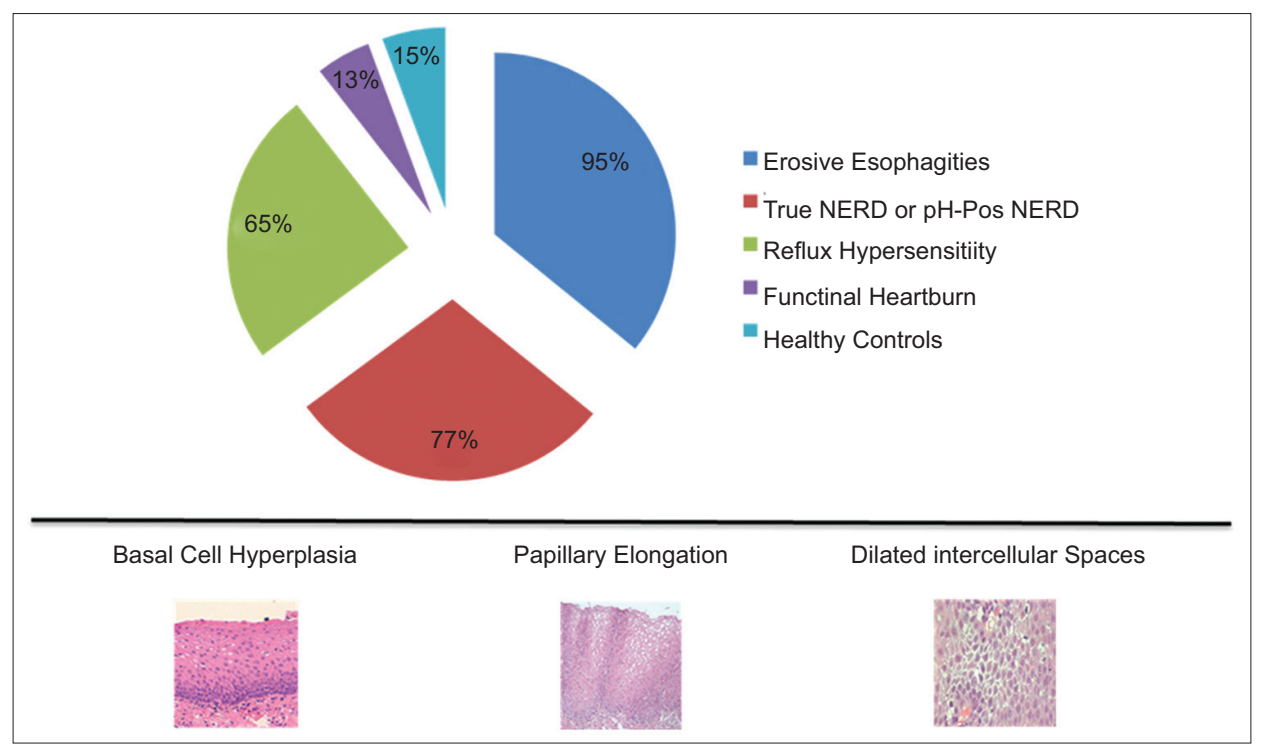

Figure 3 Expression of microscopic esophagitis in the various forms of gastroesophageal reflux disease, functional heartburn and controls NERD, non-erosive reflux disease 
swallowing and other potentially disturbing factors are absent. These authors observed that MNBI has the potential to be used as a practical and easy-to-calculate metric for evaluating the impaired status of esophageal mucosa to the point that its value expresses the real degree of microscopic esophagitis, a hallmark of both erosive reflux disease and NERD [43].

Despite the evidence of altered mucosal integrity in most NERD patients, the reinforcement of defense mechanisms and/ or its protection have rarely been considered as a therapeutic target in GERD treatment. However, drugs able to strengthen mucosal defense exist, although they have not been extensively studied in large and well-designed clinical studies enrolling the various phenotypic forms of GERD. A concise review of the compounds available, their potential indications and the results of the few clinical trials performed will follow.

\section{Sucralfate}

This old agent is the aluminum salt of sucrose sulfate, able to adsorb bile acids and forms stable complexes with protein molecules, which in turn are resistant to the proteolytic action of pepsin. It has a great affinity for inflamed mucosa due to its viscous adhesiveness and the formation of polyvalent bridges between the negatively charged sucralfate and the positively charged proteins present in high concentrations in mucosal lesions [44].

Clinical work by Orlando et al [45] has shown that sucralfate is protective against acid injury in rabbit esophagus by enhancing mucosal defenses through binding of pepsin and bile salts, neutralization of hydrogen ions by its content of aluminum hydroxide, and reduction in the permeability of esophageal mucosa to hydrogen ions.

Several clinical studies argued for the superiority of sucralfate versus placebo in alleviating GERD symptoms. For instance, 4 randomized, placebo-controlled investigations with variable doses $(1 \mathrm{~g}$ b.i.d. to $1 \mathrm{~g}$ q.i.d.) and durations of treatment $(6,8$, and 12 weeks) showed that sucralfate provided some benefit over placebo in improving symptoms and healing erosive esophagitis, even though statistical significance was not achieved in two of the studies [46]. A multicenter trial [47] demonstrated that sucralfate was better than placebo in healing endoscopic lesions, and a recent meta-analysis [48] also confirmed the superiority of sucralfate over placebo as maintenance therapy of GERD, but it must be emphasized that there are conflicting data regarding the prevention of relapse in erosive esophagitis.

Furthermore, sucralfate seems to be equally effective as $\mathrm{H}_{2} \mathrm{RAs}$ in improving reflux symptoms and in inducing mucosal healing [49]. However, the tachyphylaxis commonly seen with $\mathrm{H}_{2} \mathrm{RAs}$ given for more than 2 weeks could partly explain the non-inferiority of sucralfate, because the clinical trials lasted for 4-8 weeks on average. It should be noted that there are no studies available in the medical literature comparing sucralfate with PPIs, currently the first-choice treatment of GERD.

Some good results obtained in published studies in patients with esophageal erosions might be explained by presuming that the compound could have been in contact with the esophageal mucosa for a more or less prolonged period of time. The combination of sucralfate and $\mathrm{H}_{2}$ RAs has also been assessed in patients with reflux esophagitis in two studies [50,51]; the results concerning the control of symptoms and the healing of lesions have been conflicting, even though the number of patients enrolled in the positive trial was relatively small.

Overall, sucralfate seems to be superior to placebo and as effective as $\mathrm{H}_{2} \mathrm{RAS}$ in relieving symptoms and repairing mucosal erosions. However, the prevention of esophagitis recurrence remains an open issue, because large clinical trials have not been and probably will never be performed because of the remarkable success of PPI therapy. This is the reason why there are no comparative studies between sucralfate and PPIs.

\section{Alginate}

Alginate, alone or in combination with antacid, is used for treating symptoms of GERD, as it forms a raft floating over gastric contents and is able to reduce the number of acid reflux events [52,53]. A second relevant property of alginate is to abolish or displace the postprandial acid pocket in patients with symptomatic reflux [54]. However, it has recently been shown that this compound may have also an esophageal mucosal protective effect, because alginates have been found to be endowed with bioadhesive potential, a property due primarily to their polymer chain length and ionizable groups [55].

It has been demonstrated [56] that topical application of a sodium alginate solution to human esophageal biopsies immediately prior to acid exposure in Ussing chambers can greatly diminish the acid-induced reduction in transepithelial electrical resistance. In other words, alginates seem to be able to protect esophageal mucosa more directly by covering it for a prolonged period of time. Moreover, Woodland et al [57] confirmed this finding in a second model using $3 \mathrm{D}$ cell cultures by applying an alginate solution for $1 \mathrm{~h}$ after exposure of the system to acid. In esophageal biopsies, $60 \mathrm{~min}$ after protection with alginate solution, the acidic exposure diminished significantly as compared with a viscous control, and fluorescein-labeled alginate could be seen coating the luminal surface in all cases.

This also means that alginates have a direct protective effect on esophageal mucosa in addition to their mechanical action on refluxate and the displacement of the acid pocket. Furthermore, this adhesion to the mucosa is durable for up to $1 \mathrm{~h}$ and can therefore be another useful physical property of the drug.

As a likely consequence of the above findings, a recent clinical, randomized trial has shown that the combination of PPI + alginate was able to determine a percentage of heartburnfree days significantly superior to PPI alone during a treatment period of 28 days [58]. Furthermore, the use of alginate as addon therapy (that is giving this drug while patients continue to take a PPI) in reflux patients with partial response to these powerful antisecretory drugs, controlled heartburn and improved quality of life significantly more compared to PPI alone [59]. In contrast, in two recent randomized, double-blind studies (exploratory, $\mathrm{n}=52$; confirmatory, $\mathrm{n}=262$ ), patients taking standard-dose PPI who had breakthrough symptoms, 
were randomized to add-on Gaviscon or placebo $(20 \mathrm{~mL}$ after the three daily meals and bedtime). It was found that adding Gaviscon to PPI reduced breakthrough GERD symptoms, but a nearly equal response was observed with placebo [60]. A potential explanation of the latter negative result was that the selection of enrolled patients was based on the presence of refractory symptoms only (i.e. heartburn not responsive to PPIs) with the consequent risk of including in the study population a large number of patients with functional symptoms, who usually have good response to both drug and placebo [61-65], as observed in the two abovementioned randomized trials.

\section{Hyaluronic acid plus chondroitin sulfate}

In the last years a new medical device containing hyaluronic acid plus chondroitin sulfate has been developed in order to improve esophageal mucosal defenses. The above two substances are dispersed in a bioadhesive carrier (poloxamer 407) to form a macromolecular complex, coating the esophageal mucosa and acting as a mechanical barrier against the noxious components of refluxate, including both acid and pepsin.

Hyaluronic acid is a widespread, biologically active substance, which regulates cellular function through interaction with specific receptors [66]. This high-molecularweight glycosaminoglycan is a component of the majority of extracellular matrices and is involved in several key physiological processes, including wound repair and regeneration, morphogenesis and matrix organizations. Topical hyaluronic acid formulations are employed to treat recurrent apthous ulcerations of the oral mucosa with fast symptom relief, to which the anti-inflammatory activity of the compound may also contribute [67].

Chondroitin sulfate is a natural glycosaminoglycan that is present in the extracellular matrix surrounding cells, especially in the cartilage, skin, ligaments and tendons, where it forms an essential component of proteoglycans [68]. Current evidence shows that chondroitin sulfate fulfills important biological functions in inflammation, cell proliferation, tissue morphogenesis and wound repair. These effects are related to its capacity to interact with a large number of molecules, such as growth factors, protease inhibitors, cytokines, chemokines, and adhesion molecules [69]. Thus, the compound is endowed with immunomodulatory, anti-inflammatory and antioxidant properties. It may also display specific binding to pepsin, thus neutralizing the negative effect of this protein on esophageal mucosa.

Poloxamer 407 is a highly hydrophilic non-ionic surfactant that leads to enhanced solubilization of poorly water-soluble drugs and a prolonged release profile for many galenic applications [70]. The adhesive properties of poloxamer 407 are used to lengthen the residence times of agents in the gastrointestinal tract. Good adhesion in the esophagus with efficient diffusion of the drug into the mucosa was observed in the mouse [71].

Overall, the above-mentioned medical device works by physical means, including mechanical action, a physical barrier, and replacement of or support to organs or body functions. An experimental study using a swine model showed that perfusion of esophageal lumen with this compound is able to prevent the increase in mucosal permeability induced by acid and/or pepsin [72].

As to the clinical experience with this novel agent, there are two small prospective placebo-controlled studies showing that short-term treatment achieved significant and rapid symptom relief both in patients with erosive reflux disease [73] and NERD [74]. More recently, a prospective, double-blind, placebo-controlled trial was conducted in several Italian centers, aiming to verify the efficacy and safety of the above medical device combined with PPIs versus acid suppression alone in patients with NERD, diagnosed merely as endoscopynegative reflux disease [75]. Patients were treated for two weeks and the compound was given as a $10 \mathrm{~mL}$ stick $1 \mathrm{~h}$ after each daily meal and at bedtime. Placebo was administered in the same way and both groups also took one standard dose of PPI, 30 min before breakfast. The combination of PPI + hyaluronic acid-chondroitin sulfate was able to relieve symptoms more than PPI alone, and the improvement in quality of life was also significantly better with the former treatment, though for several items only. Of particular interest is the fact that regurgitation severity and frequency were ameliorated with the combined therapy; this is a remarkably good result if we consider that PPIs have a lesser effect on this typical reflux symptom as compared with heartburn [75]. Moreover, the safety and the palatability of the compound were found to be very good.

Overall, this study confirmed that PPIs combined with hyaluronic acid and chondroitin sulfate have a synergistic effect; therefore, mucosal protection, routinely added to acid suppression, could be extended to a larger number of patients with NERD in order to attain both symptom relief and an improvement in quality of life, thus reducing the incidence of PPI treatment failures.

\section{Concluding remarks}

Acid has attracted the attention of physiologists and doctors for many years as a fundamental factor involved in the pathogenesis of GERD and this has led to underestimation of the role of mucosal integrity in this process. The availability of new compounds, such as hyaluronic acid with chondroitin sulfate and alginates, which are able to strengthen the defensive properties of esophageal mucosa, has stimulated new research in this relevant field. It is unlikely that these agents will represent a real alternative to PPIs, but the combination of mucosal protection with acid suppression may help us manage many cases with a partial or unsatisfactory response to PPIs alone. In addition, the use of the above agents as add-on therapy to PPIs can be indicated in difficult cases. Finally, it cannot be excluded that mucosal protective compounds might prolong remission periods and therefore delay relapses, which are the rule in almost all GERD patients after PPI withdrawal. Obviously, future large and well-designed clinical trials will be necessary to prove the above hypothesis. 


\section{References}

1. El-Serag HB, Sweet S, Winchester CC, Dent J. Update on the epidemiology of gastro-oesophageal reflux disease: a systematic review. Gut 2014;63:871-880.

2. Mahadeva S, Raman MC, Ford AC, et al. Gastro-oesophageal reflux is more prevalent in Western dyspeptics: a prospective comparison of British and South-East Asian patients with dyspepsia. Aliment Pharmacol Ther 2005;21:1483-1490.

3. Savarino E, de Bortoli N, De Cassan C, et al. The natural history of gastro-esophageal reflux disease: a comprehensive review. Dis Esophagus 2017;30:1-9.

4. Savarino E, Marabotto E, Bodini G, et al. Epidemiology and natural history of gastro-esophageal reflux disease. Minerva Gastroenterol Dietol 2017;63:175-183.

5. Savarino V, Dulbecco P, de Bortoli N, Ottonello A, Savarino E. The appropriate use of proton pump inhibitors (PPIs): Need for a reappraisal. Eur J Intern Med 2017;37:19-24.

6. Savarino V, Di Mario F, Scarpignato C. Proton pump inhibitors in GORD An overview of their pharmacology, efficacy and safety. Pharmacol Res 2009;59:135-153.

7. Savarino V, Dulbecco P. Optimizing symptom relief and preventing complications in adults with gastro-oesophageal reflux disease. Digestion 2004;69 Suppl 1:9-16.

8. Galmiche JP, Letessier E, Scarpignato C. Treatment of gastrooesophageal reflux disease in adults. BMJ 1998;316:1720-1723.

9. Vigneri S, Termini R, Leandro G, et al. A comparison of five maintenance therapies for reflux esophagitis. $N$ Engl J Med 1995;333:1106-1110.

10. Fass R, Ofman JJ. Gastroesophageal reflux disease-should we adopt a new conceptual framework? Am J Gastroenterol 2002;97:1901-1909.

11. Dean BB, Gano AD Jr, Knight K, Ofman JJ, Fass R. Effectiveness of proton pump inhibitors in nonerosive reflux disease. Clin Gastroenterol Hepatol 2004;2:656-664.

12. Savarino E, Tutuian R, Zentilin P, et al. Characteristics of reflux episodes and symptom association in patients with erosive esophagitis and nonerosive reflux disease: study using combined impedance-pH off therapy. Am J Gastroenterol 2010;105:1053-1061.

13. Zentilin P, Dulbecco P, Savarino E, Giannini E, Savarino V. Combined multichannel intraluminal impedance and $\mathrm{pH}$-metry: a novel technique to improve detection of gastro-oesophageal reflux literature review. Dig Liver Dis 2004;36:565-569.

14. Sifrim D, Castell D, Dent J, Kahrilas PJ. Gastro-oesophageal reflux monitoring: review and consensus report on detection and definitions of acid, non-acid, and gas reflux. Gut 2004;53:1024-1031.

15. Savarino E, Zentilin P, Tutuian R, et al. The role of nonacid reflux in NERD: lessons learned from impedance-pH monitoring in 150 patients off therapy. Am J Gastroenterol 2008;103:2685-2693.

16. Savarino E, Marabotto E, Zentilin P, et al. The added value of impedance-pH monitoring to Rome III criteria in distinguishing functional heartburn from non-erosive reflux disease. Dig Liver Dis 2011;43:542-547.

17. Gyawali CP. Redeeming clinical value of esophageal $\mathrm{pH}$ impedance monitoring. Clin Gastroenterol Hepatol 2016;14:47-49.

18. Savarino E, Zentilin P, Savarino V. NERD: an umbrella term including heterogeneous subpopulations. Nat Rev Gastroenterol Hepatol 2013;10:371-380.

19. Aziz Q, Fass R, Gyawali CP, Miwa H, Pandolfino JE, Zerbib F. Esophageal disorders. Gastroenterology 2016;150:1368-1379.

20. Scarpignato C. Poor effectiveness of proton pump inhibitors in non-erosive reflux disease: the truth in the end! Neurogastroenterol Motil 2012;24:697-704.

21. Zentilin P, Savarino V, Mastracci L, et al. Reassessment of the diagnostic value of histology in patients with GERD, using multiple biopsy sites and an appropriate control group. Am J Gastroenterol 2005; 100:2299-2306.

22. Mastracci L, Spaggiari P, Grillo F, et al. Microscopic esophagitis in gastro-esophageal reflux disease: individual lesions, biopsy sampling, and clinical correlations. Virchows Arch 2009;454:31-39.

23. Caviglia R, Ribolsi M, Maggiano N, et al. Dilated intercellular spaces of esophageal epithelium in nonerosive reflux disease patients with physiological esophageal acid exposure. Am J Gastroenterol 2005;100:543-548.

24. Ribolsi M, Perrone G, Caviglia R, et al. Intercellular space diameters of the oesophageal epithelium in NERD patients: head to head comparison between light and electron microscopy analysis. Dig Liver Dis 2009;41:9-14.

25. Fiocca R, Mastracci L, Milione M, Parente P, Savarino V; Società Italiana di Anatomia Patologica e Citopatologia Diagnostica/ International Academy of Pathology, Italian division (SIAPEC/ IAP). Microscopic esophagitis and Barrett's esophagus: the histology report. Dig Liver Dis 2011;43 Suppl 4:S319-S330.

26. Yerian L, Fiocca R, Mastracci L, et al. Refinement and reproducibility of histologic criteria for the assessment of microscopic lesions in patients with gastroesophageal reflux disease: the Esohisto Project. Dig Dis Sci 2011;56:2656-2665.

27. Savarino E, Zentilin P, Mastracci L, et al. Microscopic esophagitis distinguishes patients with non-erosive reflux disease from those with functional heartburn. J Gastroenterol 2013;48:473-482.

28. Roman S, Gyawali CP, Savarino E, et al; GERD consensus group. Ambulatory reflux monitoring for diagnosis of gastro-esophageal reflux disease: Update of the Porto consensus and recommendations from an international consensus group. Neurogastroenterol Motil 2017 Mar 31. doi: 10.1111/nmo.13067. [Epub ahead of print]

29. Farré R, Fornari F, Blondeau K, et al. Acid and weakly acidic solutions impair mucosal integrity of distal exposed and proximal non-exposed human oesophagus. Gut 2010;59:164-169.

30. Farré R, van Malenstein H, De Vos R, et al. Short exposure of oesophageal mucosa to bile acids, both in acidic and weakly acidic conditions, can impair mucosal integrity and provoke dilated intercellular spaces. Gut 2008;57:1366-1374.

31. Vela MF, Camacho-Lobato L, Srinivasan R, Tutuian R, Katz PO, Castell DO. Simultaneous intraesophageal impedance and $\mathrm{pH}$ measurement of acid and nonacid gastroesophageal reflux: effect of omeprazole. Gastroenterology 2001;120:1599-1606.

32. Calabrese C, Bortolotti M, Fabbri A, et al. Reversibility of GERD ultrastructural alterations and relief of symptoms after omeprazole treatment. Am J Gastroenterol 2005; 100:537-542.

33. Fiocca R, Mastracci L, Engström C, et al; LOTUS trial collaborators. Long-term outcome of microscopic esophagitis in chronic GERD patients treated with esomeprazole or laparoscopic antireflux surgery in the LOTUS trial. Am J Gastroenterol 2010; 105:1015-1023.

34. Orlando RC. The integrity of the esophageal mucosa. Balance between offensive and defensive mechanisms. Best Pract Res Clin Gastroenterol 2010;24:873-882.

35. Orlando RC. Review article: oesophageal mucosal resistance. Aliment Pharmacol Ther 1998;12:191-197.

36. Farrè R. Pathophysiology of gastro-esophageal reflux disease: a role for mucosa integrity? Neurogastroenterol Motil 2013;25:783-799.

37. Martinucci I, de Bortoli N, Savarino E, et al. Esophageal baseline impedance levels in patients with pathophysiological characteristics of functional heartburn. Neurogastroenterol Motil 2014;26:546-555.

38. Ravi K, Geno DM, Vela MF, Crowell MD, Katzka DA. Baseline impedance measured during high-resolution esophageal impedance manometry reliably discriminates GERD patients. Neurogastroenterol Motil 2017;29(5).

39. Vaezi MF, Choksi Y. Mucosal impedance: a new way to diagnose 
reflux disease and how it could change your practice. Am J Gastroenterol 2017;112:4-7.

40. de Bortoli N, Martinucci I, Savarino E, et al. Association between baseline impedance values and response proton pump inhibitors in patients with heartburn. Clin Gastroenterol Hepatol 2015;13:10821088.e1.

41. Frazzoni M, Savarino E, de Bortoli N, et al. Analyses of the postreflux swallow-induced peristaltic wave index and nocturnal baseline impedance parameters increase the diagnostic yield of patients with reflux disease. Clin Gastroenterol Hepatol 2016;14:40-46.

42. Frazzoni M, De Bortoli N, Frazzoni L, et al. Impairment of chemical clearance and mucosal integrity distinguishes hypersensitive esophagus from functional heartburn. $J$ Gastroenterol 2017;52:444-451.

43. Frazzoni M, De Bortoli N, Frazzoni L, et al. The added diagnostic value of postreflux swallow-induced peristaltic wave index and nocturnal baseline impedance in refractory reflux disease studied with on-therapy impedance-pH monitoring. Neurogastroenterol Motil 2017;29(3).

44. Nagashima R. Mechanisms of action of sucralfate. J Clin Gastroenterol 1981;3:117-127.

45. Orlando RC, Powel DW. Effect of sucralfate on esophageal epithelial resistance to acid in the rabbit. Gastroenterology 1984;86:1201A.

46. Surdea-Blaga T, Băncilă I, Dobru D et al. Mucosal protective compounds in the treatment of gastroesophageal reflux disease. A position paper based on evidence of the Romanian Society of Gastroenterology. J Gastrointest Liver Dis 2016;25:537-546.

47. Williams RM, Orlando RC, Bozymski EM, et al. Multicenter trial of sucralfate suspension for the treatment of reflux esophagitis. Am J Med 1987;83:61-66.

48. Donnellan C, Sharma N, Preston C, Moayyedi P. Medical treatment for the maintenance therapy of reflux esophagitis and endoscopic negative reflux disease. Cochrane Database Syst Rev 2005;(2):CD003245.

49. Bremner CG, Marks IN, Segal I, Simjee A. Reflux esophagitis therapy: sucralfate versus ranitidine in a double blind multicenter trial. Am J Med 1991;91:119S-122S.

50. Schotborgh RH, Hameeteman W, Dekker W, et al. Combination therapy of sucralfate and cimetidine, compared with sucralfate monotherapy, in patients with peptic reflux esophagitis. Am J Med 1989;86:77-80.

51. Herrera JL, Shay SS, McCabe M, Peura DA, Johnson LF. Sucralfate used as adjunctive therapy in patients with severe erosive peptic esophagitis resulting from gastroesophageal reflux. Am J Gastroenterol 1990;85:1335-1338.

52. Kahrilas PJ, Jonsson A, Denison H, Wernersson B, Hughes N, Howden CW. Regurgitation is less responsive to acid suppression than heartburn in patients with gastroesophageal reflux disease. Clin Gastroenterol Hepatol 2012;10:612-619.

53. Zentilin P, Dulbecco P, Savarino E, et al. An evaluation of the antireflux properties of sodium alginate by means of combined multichannel intraluminal impedance and $\mathrm{pH}$-metry. Aliment Pharmacol Ther 2005;21:29-34.

54. Savarino E, de Bortoli N, Zentilin P, et al. Alginate controls heartburn in patients with erosive and nonerosive reflux disease. World J Gastroenterol 2012;18:4371-4378.

55. Kwiatek MA, Roman S, Fareeduddin A, Pandolfino JE, Kahrilas PJ. An alginate-antacid formulation (Gaviscon Double Action Liquid) can eliminate or displace the postprandial 'acid pocket' in symptomatic GERD patients. Aliment Pharmacol Ther 2011;34:59-66.

56. Smart JD, Kellaway IW, Worthington HE. An in-vitro investigation of mucosa-adhesive materials for use in controlled drug delivery. J Pharm Pharmacol 1984;36:295-299.
57. Woodland P, Lee C, Duraisamy Y, et al. Assessment and protection of esophageal mucosal integrity in patients with heartburn without esophagitis. Am J Gastroenterol 2013;108:535-543.

58. Woodland P, Batista.Lima F, Lee C, Preston SL, Dettmar P, Sifrim D. Topical protection of human esophageal mucosal integrity. Am J Physiol Gastrointest Liver Physiol 2015;308:G975-G980.

59. Manabe N, Haruma K, Ito M, et al. Efficacy of adding sodium alginate to omeprazole in patients with nonerosive reflux disease: a randomized clinical trial. Dis Esophagus 2012;25:373-380.

60. Reimer C, Lødrup AB, Smith G, Wilkinson J, Bytzer P. Randomised clinical trial: alginate (Gaviscon Advance) vs. placebo as add-on therapy in reflux patients with inadequate response to a once daily proton pump inhibitor. Aliment Pharmacol Ther 2016;43:899-909.

61. Coyle C, Crawford G, Wilkinson J, Thomas SJ, Bytzer P. Randomised clinical trial: addition of alginate-antacid (Gaviscon Double Action) to proton pump inhibitor therapy in patients with breakthrough symptoms. Aliment Pharmacol Ther 2017;45:1524-1533.

62. de Bortoli N, Ottonello A, Zerbib F, Sifrim D, Gyawali CP, Savarino E. Between GERD and NERD: the relevance of weakly acidic reflux. Ann N Y Acad Sci 2016;1380:218-229.

63. Savarino E, Pohl D, Zentilin P, et al. Functional heartburn has more in common with functional dyspepsia than with non-erosive reflux disease. Gut 2009;58:1185-1191.

64. Zentilin P, Marabotto E, Pellegatta G, et al. Complexity and diversity of GERD phenotypes. Minerva Gastroenterol Dietol 2017;63:198-204.

65. de Bortoli N, Frazzoni L, Savarino EV, et al. Functional heartburn overlaps with irritable bowel syndrome more often than GERD. Am J Gastroenterol 2016;111:1711-1717.

66. Gaffney J, Matou-Nasri S, Grau-Olivares M, Slevin M. Therapeutic applications of hyaluronan. Mol Biosyst 2010;6:437-443.

67. Ialenti A, Di Rosa M. Hyaluronic acid modulates acute and chronic inflammation. Agents Actions 1994;43:44-47.

68. Lauder RM. Chondroitin sulphate: a complex molecule with potential impacts on a wide range of biological systems. Complement Ther Med 2009; 17:56-62.

69. Volpi N. Anti-inflammatory activity of chondroitin sulphate: new functions from an old natural macromolecule. Inflammopharmacology 2011;19:299-306.

70. Ramya Devi D, Sandhya P, Vedha Hari BN. Poloxamer: a novel functional molecule for drug delivery and gene therapy. J Pharm Sci Res 2013;5:159-165.

71. Dumortier G, Grossiord JL, Agnely F, Chaumeil JC. A review of poloxamer 407 pharmaceutical and pharmacological characteristics. Pharm Res 2006;23:2709-2728.

72. Tang M, Dettmar P, Batchelor H. Bioadhesive oesophageal bandages: protection against acid and pepsin injury. Int J Pharm 2005;292:169-177.

73. Palmieri B, Corbascio D, Capone S, Lodi D. Preliminary clinical experience with a new natural compound in the treatment of esophagitis and gastritis: symptomatic effect. Trends Med 2009;9:219-225.

74. Palmieri B, Merighi A, Corbascio D, Rottigni V, Fistetto G, Esposito A. Fixed combination of hyaluronic acid and chondroitin-sulphate oral formulation in a randomized double blind, placebo controlled study for the treatment of symptoms in patients with non-erosive gastroesophageal reflux. Eur RevJ+1

Med Pharmacol Sci 2013;17:3272-3278.

75. Savarino V, Pace F, Scarpignato C; Esoxx Study Group. Randomised clinical trial: mucosal protection combined with acid suppression in the treatment of non-erosive reflux disease - efficacy of Esoxx, a hyaluronic acid-chondroitin sulphate based bioadhesive formulation. Aliment Pharmacol Ther 2017;45:631-642. 